\title{
GLEMOK - NOVEL METHOD FOR CATCHMENT MOISTURE DETERMINATION USING HIGH-RESOLUTION SOIL MAP
}

\author{
BAZIAK, B. ${ }^{*}$ - GĄDEK, W. - SZCZEPANEK, R. \\ Department of Water Engineering and Water Management of the Cracow University of \\ Technology, Cracow, Poland \\ *Corresponding author \\ e-mail: beata.baziak@iigw.pk.edu.pl \\ (Received $8^{\text {th }}$ Jan 2019; accepted $13^{\text {th }}$ Jun 2019)
}

\begin{abstract}
One of the crucial elements having a direct impact on rainfall-runoff transformation is soil moisture of the catchment. Moisture conditions can be expressed by physical catchment descriptors, like PROPWET or FLATWET. Their values are represented by ratio between time when the soil is wet and analysed period, using wet-dry threshold $R_{g}$. The wet-dry threshold is based on climatic data and is constant for the PROPWET $\left(R_{g}=6 \mathrm{~mm}\right)$ and for FLATWET $\left(R_{g}=8.5 \mathrm{~mm}\right)$. The purpose of the present publication is to define a descriptor suitable for any area in Europe. The authors propose novel descriptor (GLEMOK) using additionally physical soil properties. Public SoilGrids250m soil database was applied, which served to develop a high-resolution soil map and $\mathrm{pF}$ curves. For the Raba river catchment (research area) the $R_{g}$. threshold is equal $11.5 \mathrm{~mm}$. The GLEMOK descriptor for this research area has proportionally larger values than the other two, which is closer to real water regime in this region of Poland. The novel descriptor GLEMOK using physical soil properties is more universal compared to PROPWET and FLATWET. Use of the global SolidGrids250m soil database enables implementation of this method in any area in Europe.
\end{abstract}

Keywords: PROPWET, FLATWET, SMD, SoilGrids250m, database, wet-dry threshold

\section{Introduction}

So far, in hydrology, the problem of forecasting flow characteristics has been solved using mathematical modelling for which unambiguous procedures have not been determined (O'Connor, 2014). In United Kingdom, a methodology has been developed for the needs of engineering practice, which has been called design hydrology (Reed, 1999; Faulkner, 1999; Robson and Reed, 1999; Houghton-Carr, 1999; Bayliss, 1999). In design hydrology, the physical catchment descriptors (PCDs) play a fundamental role (Bayliss, 1999; Mills et al., 2014) in quantitative and qualitative description of the given catchment. Based on these descriptors, hydrological characteristics used in the design, management and analysis of changes taking place in the catchment can be determined. PCDs can be divided into three groups:

- fixed - related to the topography, orography and hydrography of the catchment, including for instance the catchment area, the river network density, the watercourse slope, etc.

- variable - representing spatial development of the catchment, for instance forest land cover, urbanization, length of watercourses under anthropopressure, etc.

- process-related - for instance, moisture conditions of the catchment, surface retention, flood attenuation by channels and lakes, urbanization pressure on the outflow, etc.

Process descriptors form the foundations for the development of formulas that allow linking engineering hydrology with dynamic hydrology, which until now has been used 
in mathematical hydrological modelling. Such a combination provides the opportunity to extend the scope of its applicability to new areas, related for instance to determining the impact of climate change on hydrological characteristics (Apel et al., 2006; Vrijling et al., 1998; Zeleňáková et al., 2017) or to the impact of urbanized areas on flood risk (Zevenbergen et al., 2011).

Among the descriptors used around the world to define the dynamics of the transformation of rainfall (precipitation) into runoff, two are particularly noteworthy in terms of describing the watercourse supply. These are the PROPWET and BFI descriptors (Bayliss, 1999; Reed, 2007; Mills, 2014), which determine what part of the precipitation is transformed into runoff in the form of surface or subsurface runoff. The PROPWET descriptor is determined from the soil moisture deficit (SMD) (Hubbard et al., 2007), using the Hybrid Soil Moisture Deficit Model (Allen et al., 1998; Reed, 2007). SMD is calculated as follows:

$$
S M D_{t}=S M D_{t-1}-\text { Rain }+E T_{a}-\text { Drain }
$$

where:

- $S M D_{t}, S M D_{t-1}$ - the SMDs on day $\mathrm{t}$ and day $\mathrm{t}-1$ respectively $(\mathrm{mm})$.

- Rain - the daily precipitation $\left(\mathrm{mm} \mathrm{d}^{-1}\right)$.

- $E T_{a}$ - the daily actual evapotranspiration for a reference grass crop $\left(\mathrm{mm} \mathrm{d}^{-1}\right)$.

- Drain - the amount of water drained daily by percolation and/or overland flow $\left(\mathrm{mm} \mathrm{d}^{-1}\right)$.

Climatic data used to determine the SMD include: atmospheric precipitation, temperature and air humidity, wind speed, and net radiation (Narasimhan and Srinivasan, 2005). Atmospheric precipitation is divided into effective precipitation and soil retention (Figure 1).

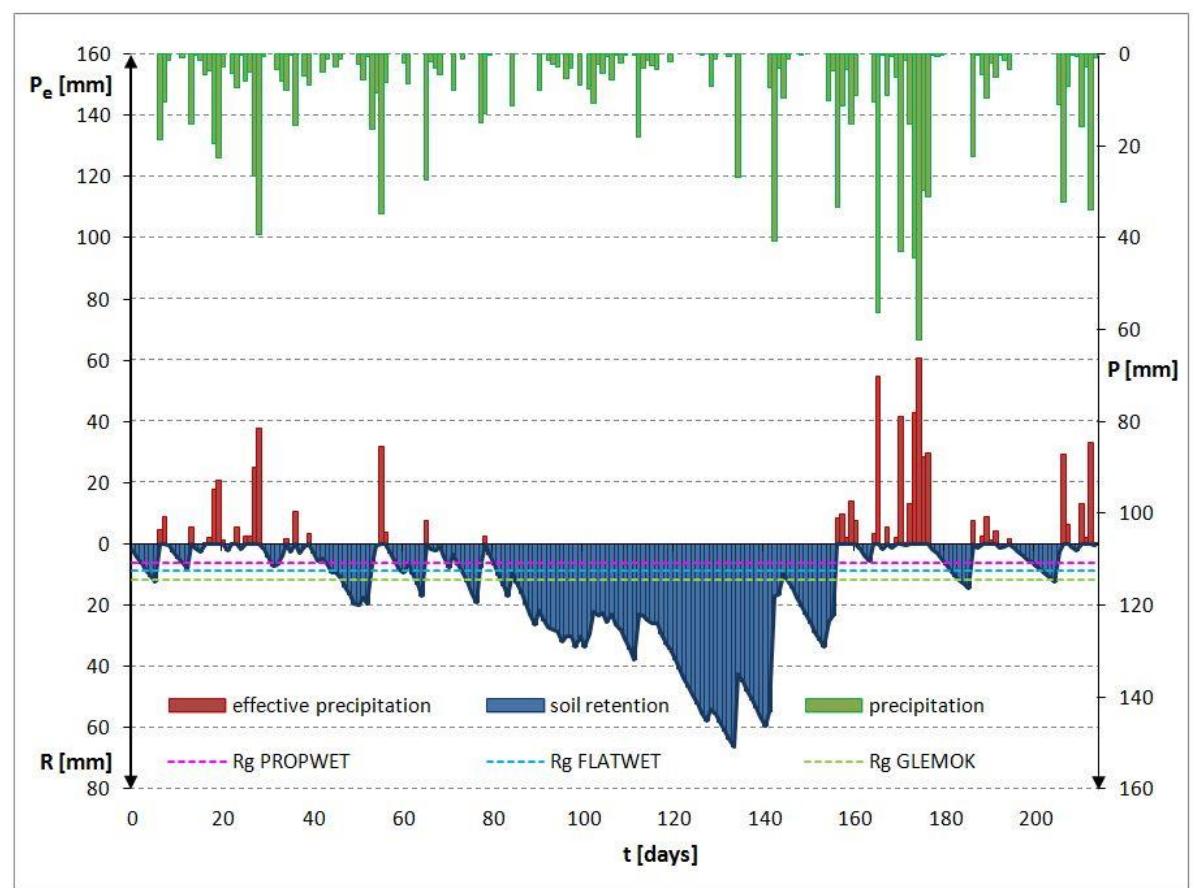

Figure 1. Division of atmospheric precipitation into surface runoff and soil retention using the SMD 
The soil moisture deficit assumes only positive values and represents soil retention $R$. In the case of precipitation exceeding the soil retention, excess precipitation flows down as surface runoff, and the $S M D$ is set to 0 value. Increase in the $S M D$ humidity deficit means soil drying, whereas the reduction of its value means the replenishment of water in soil by precipitation. The values of the SMD which are lower than the threshold values, presented in the form of dashed lines (Figure 1), denote wet soil. Dry soil is represented by values greater than the threshold values, in which case water is available only for plants.

Based on the SMD the PROPWET descriptor was designated. It represents the share of time in which the soil remains wet compared to the whole of the analysed period. For this purpose, it is necessary to determine the threshold of soil division $R_{g}$, into wet soil and dry soil. The search for the threshold between wet and dry soil is carried out in the optimization process. For a given threshold value (for instance $R_{g}=2.5 \mathrm{~mm}$ ) for all climate stations, the share of time during which the soil remains wet is calculated (PROPWET 2.5 ). The next step is to determine the differences between the calculated PROPWET $_{2.5}$ values for all pairs of climate stations. On this basis, the average value of these differences is calculated for a given threshold $(2.5 \mathrm{~mm})$. The threshold is determined for the assumed objective function, which is the maximum of the average differences. The threshold is chosen to maximise the inter-site variation in PROPWET across all gauged sites. For the United Kingdom $R_{g}=6 \mathrm{~mm}$ (Reed, 2007), for the Ireland $R_{g}=8.5 \mathrm{~mm}$ (Schulte et al., 2005), thus PROPWET descriptor has been renamed to FLATWET and is used only in Ireland (Figure 1).

FLATWET and PROPWET descriptors were developed for United Kingdom and Ireland, which according to the Köppen-Geiger division (Kottek et al., 2006) lies in the same climate zone as Poland ( $\mathrm{Cfb}$ - warm temperate climate, fully humid, warm summer). The amplitude of air temperature changes throughout the year in Poland is greater than in the United Kingdom, resulting in four seasons. When estimating the values of these descriptors, the winter period poses a problem when the ground is frozen, and the precipitation occurs in the form of snow. This involves the growing season, which in Poland is between April and October (Olszewski and Żmudzka, 2000). Then the catchment's behaviour is completely different than in the growing season. In contrast to British Isles, the number of days with Tmin $<0^{\circ} \mathrm{C}$ ranges from less than 100 days on the Baltic coast to over 140 days in the east of Poland (Kejna et al., 2009). This causes freezing of the soil, which is associated with a change in water conduction properties. Under such conditions, the permeable soil becomes impermeable, sublimation or evaporation occurs without transpiration, and the precipitation occurs in solid form (snow). The outflow from the catchment in this period comes mainly from groundwater, whereas the surface runoff from the melting snow (thaw or snow-melt). For this reason, for the territory of Poland, the winter period should be omitted in the calculations related to establishing the threshold between wet and dry soil.

The purpose of the present publication is to define a descriptor that will take into account the moisture conditions of the catchment, suitable for any area in Europe. The authors propose the GLEMOK descriptor, specifying the share of time during which the soil remains wet, based on the PROPWET descriptor elaborated in United Kingdom and FLATWET descriptor used in Ireland. However, during the development of the descriptor, the winter period have been eliminated from the calculations, therefore the principle of the descriptor's determination had to be changed in relation to the original model. 
Determination of the threshold between wet and dry soil should be carried out for the area of Poland in a different way than for the PROPWET or FLATWET. For the latter two descriptors, the threshold is determined for climatic data from the whole calendar year. The very idea of PROPWET and FLATWET originates from dynamic hydrology, in which the issues related to the process of infiltration form the basis for solving the set of equations for the rainfall-runoff transformation (Eagleson, 1970; Ozga-Zielińska et al., 2002). One of the characteristics describing the physical properties of soil is the $\mathrm{pF}$ curve (Eq. 2), which illustrates the relationship between soil water content $\theta$ and soil matric potential $h_{s}$ affecting water molecules in soil (Figure 2).

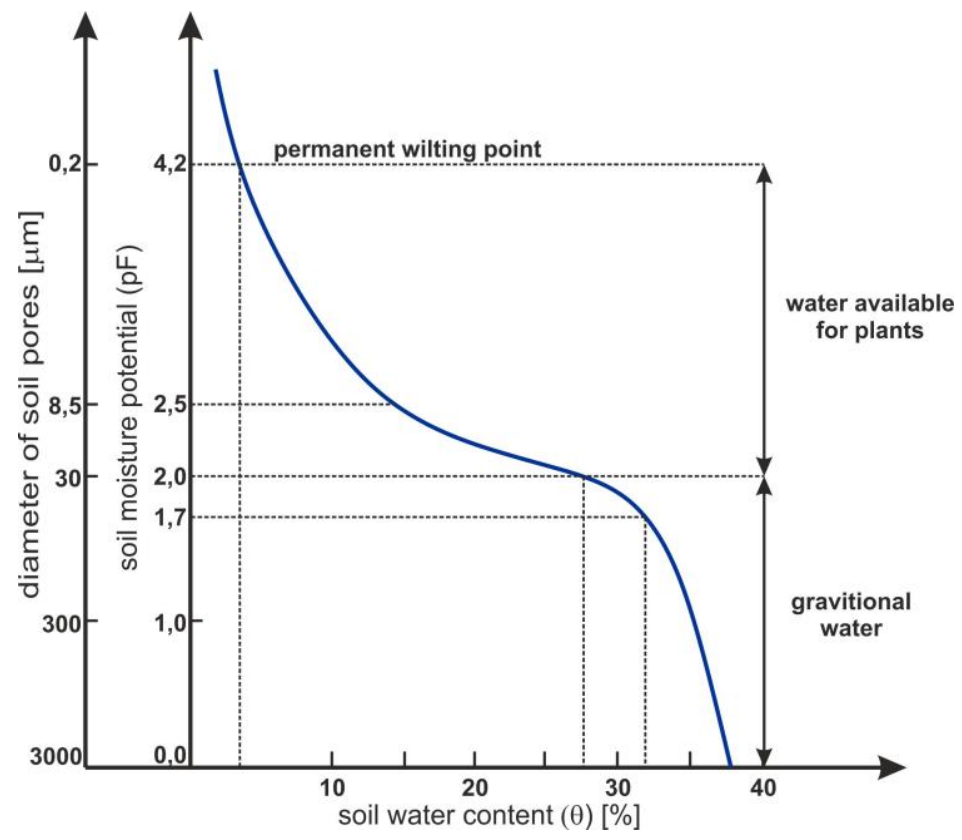

Figure 2. Sample pF curve of the soil

$$
p F=\log \left(-h_{s}\right)
$$

where:

$h_{s}$ - soil matric potential (suction pressure) $(\mathrm{cm})$.

On the basis of the $\mathrm{pF}$ curve, it is possible to determine points, which determine the state of soil moisture. These are:

$-h_{s}=-50 \mathrm{~cm}(p F=1.7)-$ from the value of $h_{s}=-50 \mathrm{~cm}$ to the value of $h_{s}=0 \mathrm{~cm}$ water in the soil moves mainly due to gravity (force of attraction) and it is assumed that this water is not available for plants, but it takes part in the direct supply of watercourses.

$-h_{s}=-100 \mathrm{~cm}(p F=2.0)-$ from the value of $h_{s}=-100 \mathrm{~cm}$ to the value of $h_{s}=-50 \mathrm{~cm}$ water moves mainly under the influence of gravity, and the process of evapotranspiration begins.

- $h_{s}=-300 \mathrm{~cm}(p F=2.5)$ - water is readily available for plants, and with lower values of suction pressure, the evapotranspiration process is gradually reduced.

$-h_{s}=-15,000 \mathrm{~cm}(\mathrm{pF}=4.2)$ is the point of permanent wilting of plants, and at this point evapotranspiration disappears. 
In 1986, Driessen proposed the equation describing $\mathrm{pF}$ curves for soils (Eq. 3), according to the European classification:

$$
\theta\left(h_{s}\right)=\theta_{s} e^{-\mu\left[\ln \left(-h_{s}\right)\right]^{2}}
$$

where:

- $\theta_{s}$ - maximum volumetric humidity $\left(\mathrm{cm}^{3} \mathrm{~cm}^{-3}\right)$.

- $\mu$-parameter dependent on the type of the soil $\left(\mathrm{cm}^{-2}\right)$.

Soil classification can be made using the grain size information, which is described in the Feret's diagram shown in Figure 3.

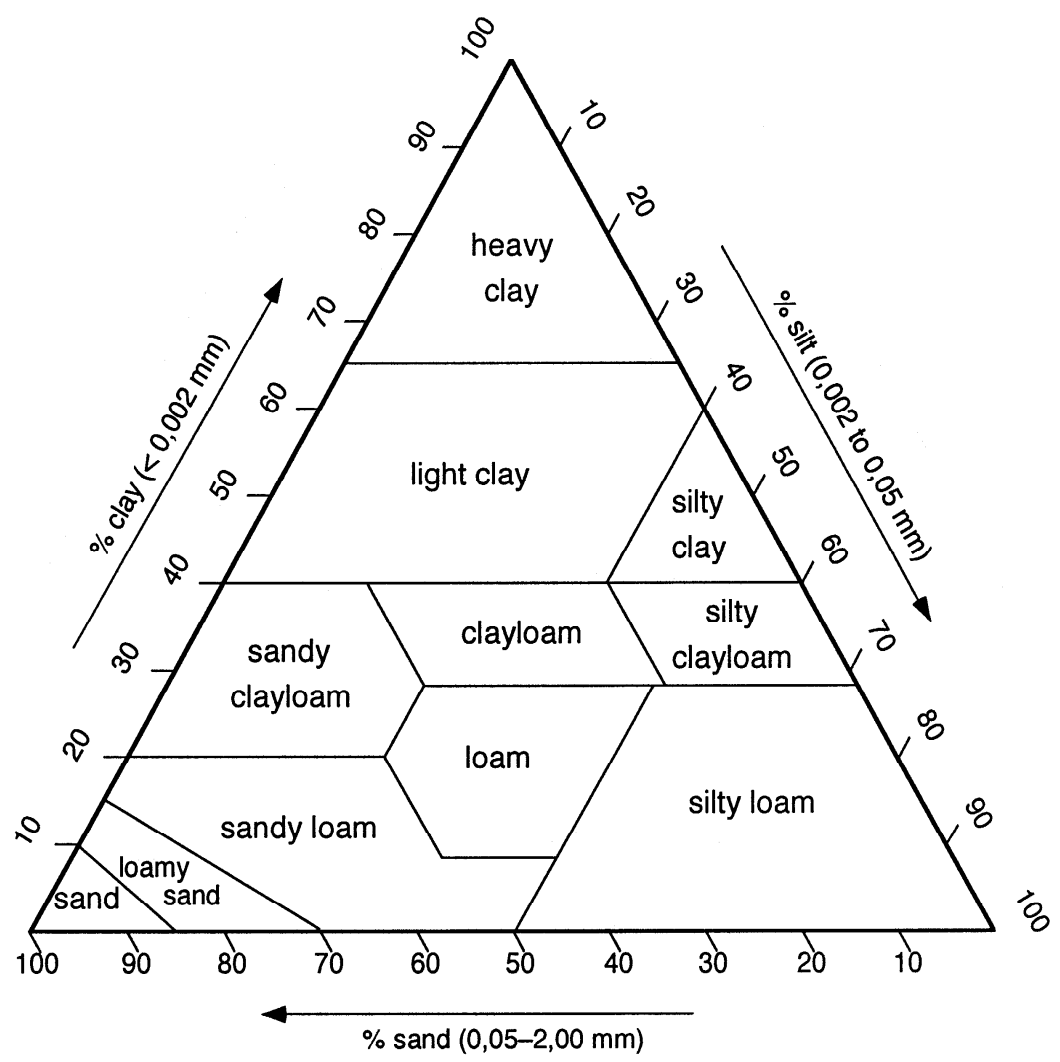

Figure 3. Feret's diagram according to the European classification of soils (Dreissen, 1986)

\section{Materials and methods}

\section{The area and data under study}

The Raba river catchment had been adopted as the study area. Raba river is a rightbank tributary of the Vistula river. It is about $132 \mathrm{~km}$ long and covers an area of $1537.1 \mathrm{~km}^{2}$, flowing through three hydrological regions. The largest part of the catchment is located in the Carpathian zone, representing the mountainous terrain. The remaining part is located in the upland area, whereas the estuary part represents the lowlands. The average elevation of the catchment is about $500 \mathrm{~m}$ above sea level. The highest point of the catchment is Turbacz mountain, at $1310 \mathrm{~m}$ above sea level, and the lowest is $180 \mathrm{~m}$ above sea level, at the point where Raba enters the Vistula river. 
Within the Raba river catchment 9 water gauges were used in calculation, 7 of them located upstream water reservoir in Dobczyce. Figure 4 shows sub-catchments for particular water gauges.

The values of the mean annual precipitation from the summer half-year, for all computational cross-sections, are presented in Table 1.

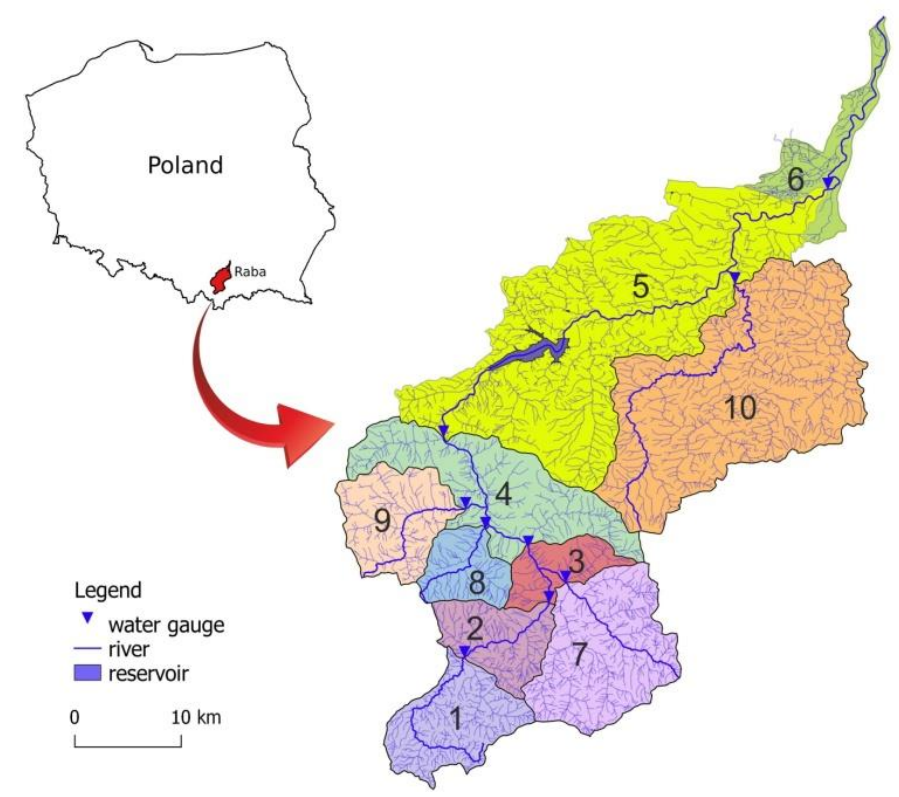

Figure 4. Location of water gauges in the catchment of Raba river, in accordance with Table 1

Table 1. Values of mean annual precipitation from the summer half-year, for computational cross-sections of Raba river catchment

\begin{tabular}{c|c|c|c}
\hline No. & \multirow{2}{*}{ River } & Gauge station & $\begin{array}{c}\text { Mean rainfall in the summer half-year } \\
{[\mathbf{m m}]}\end{array}$ \\
\hline 1 & & Rabka & 568 \\
2 & & Mszana Dolna & 550 \\
3 & & Kasinka Mała & 540 \\
4 & RABA & Stróża & 533 \\
5 & & Proszówki & 519 \\
6 & & Outlet to Wisła & 514 \\
\hline 7 & & Mszana Dolna & 534 \\
\hline 8 & MSZANKA & Lubień & 525 \\
\hline 9 & LRZCZÓNKA & Krzczonów & 525 \\
\hline 10 & STRADOMKA & Stradomka & 508 \\
\hline
\end{tabular}

The calculations were carried out for the PROPWET, FLATWET and GLEMOK descriptors, for a 30-year measurement data series from April 1 to October 31 in the years 1983-2012. For each descriptor, the appropriate wet-dry threshold was accepted. Climatic data, including atmospheric precipitation in the years 1983-2006, comes from the station in Stróża, run by the Hydrology Department of the Institute of Engineering and Water Management of the Cracow University of Technology, whereas the data for the period 2007-2012 was obtained from the climate station of the IMGW PIB in Dobczyce. Small distance between Stróża and Dobczyce stations $(15 \mathrm{~km})$ with the same 
measurement conditions (standard Hellmann rain gauge) enabled merge of data from those two series (Noone et al., 2016). The non-parametric Mann-Whitney-Wilcoxon test for yearly precipitation, with resulting $p=0.001$ at significance level $\alpha=0.05$, confirmed hypothesis on series homogeneity (Yue and Wang, 2002). The spatial distribution of atmospheric precipitation and field evaporation for the whole catchment was elaborated on the basis of rainfall maps and evapotranspiration index for grass, published by IMGW PIB in the "Hydrological Atlas of Poland" (IMGW, 1987).

In order to determine the type of soils, raster layers of soil granulometry were used, derived from the SoilGrids250m project (Hengl et al., 2017). Soil grain size is available in the form of three fractions (sandy, loamy and silty), for seven depths in the soil profile $(0,5,15,30,60,100$ and $200 \mathrm{~cm})$.

SoilGrids250m database (https://soilgrids.org) is one of the few global soil information resources, making it possible to determine the type of soil in any area of the globe, with a spatial resolution of about $250 \mathrm{~m}$ (Hengl et al., 2017). The sources of data for the development of this database included:

- Approximately 150000 soil profiles.

- Expert profiles for non-monitored areas.

- 158 satellite products, including MODIS land products, SRTM DEM, as well as climatic and lithological data, etc.

- Machine learning algorithms.

The data are available to the public in the form of raster layers on a free-of-charge license basis (ODbL - Open Database License).

\section{Methodology}

Using the Feret's diagram (Figure 3) and the grain size information for selected depths $(0,5,15$ and $30 \mathrm{~cm})$, the type of soil was determined. This was accomplished by developed application (https://gitlab.com/OpenHydrology/soil-map), using the Python 3.7 programming language, with rasterio and python-ternary packages (Harper et al., 2015). Raster layers with a spatial resolution of $250 \mathrm{~m}$ from SoilGrids $250 \mathrm{~m}$ project were used as input data. For the processing and visualization of the spatial data QGIS 2.18 software was used (Sherman, 2014).

As a result, a high-resolution raster map of soils for the area of Poland was generated (Figure 5). This map was used to determine the threshold between wet and dry soil for the GLEMOK descriptor, which is determined for each soil individually. The name of this new descriptor is abbreviation of "wet soil" term (Polish: GLEba MOKra). Precipitation events causes the soil became moist, so descriptor value should exceed relative number of days with precipitation. Relative number of days with precipitation can be calculated as ratio between average number of days with precipitation and growing season lengths.

This is a different approach than in the PROPWET and FLATWET descriptors, where the threshold value is determined arbitrarily, by using optimization methods. When determining the wet-dry threshold in the GLEMOK descriptor, $\mathrm{pF}$ curves were applied that characterize the properties of a given soil type, as presented in Table 2.

Procedure for calculating the GLEMOK descriptor:

1. Based on climatic data, the soil moisture deficit SMD in the catchment, up to the gauge cross-section, is determined.

2. Based on the soil map, the average value of the wet-dry threshold $R_{g}$ is determined (Table 3) according to the following ratio: 


$$
\boldsymbol{R}_{g}=\frac{\sum_{i=1}^{n}\left(R_{g}^{i} \cdot A_{g}^{i}\right)}{\sum_{i=1}^{n} A_{g}^{i}}
$$

where:

$\boldsymbol{R}_{\boldsymbol{g}}^{\boldsymbol{i}}$ - threshold between wet and dry soil, for a particular type of soil $i(\mathrm{~mm})$.

$\boldsymbol{A}_{\boldsymbol{g}}^{\boldsymbol{i}}$ - area occupied by a particular type of soil $i\left(\mathrm{~km}^{2}\right)$.

$n$ - number of soil types in the catchment (-).

3. Based on the soil moisture deficit and the calculated average wet-dry threshold $R_{g}$ (Eq. 4), the time during which the soil remains wet is calculated.

4. The value of the GLEMOK descriptor is defined as the ratio of time during which the soil remains wet to the considered measurement period.

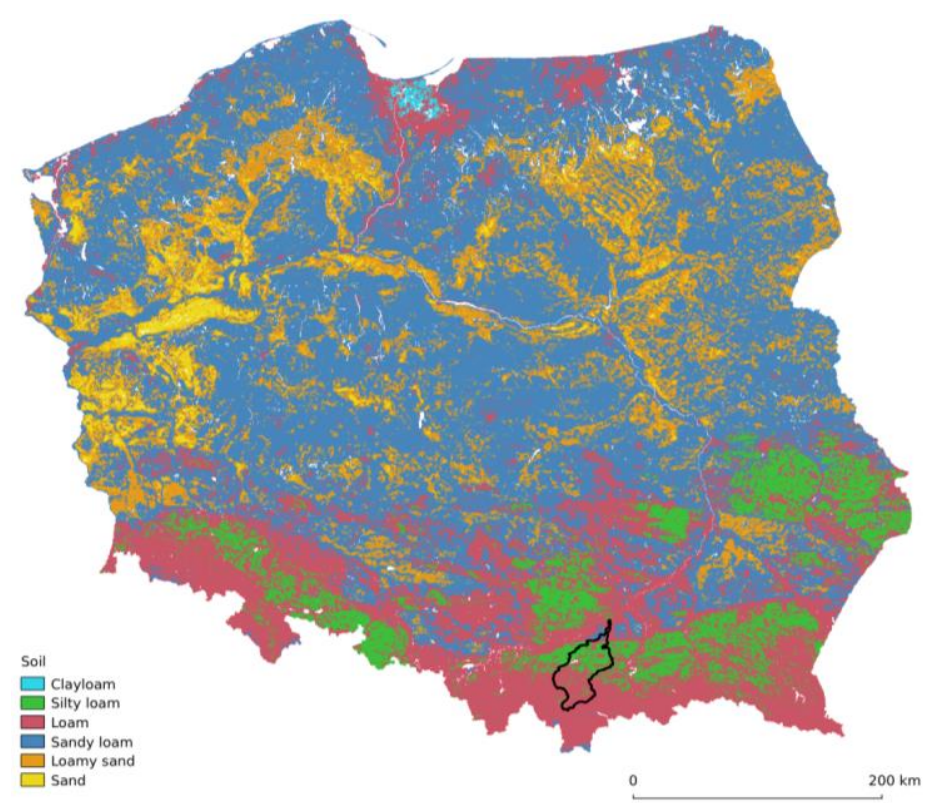

Figure 5. Classification of soils for the area of Poland, based on granulometric data from the SoilGrids250m project (https://soilgrids.org). Raba catchment is outlined

Table 2. Values of maximum volumetric humidity $\Theta_{s}$, parameter $\mu$ (Driessen, 1986) and volumetric humidity $\theta$ for suction pressure $p F=1.7$ and $p F=2.0$

\begin{tabular}{c|c|c|c|c}
\hline Type of the soil & $\begin{array}{c}\boldsymbol{\Theta}_{\mathbf{s}} \\
{\left[\mathbf{c m}^{\left.\mathbf{3} / \mathbf{c m}^{3}\right]}\right.}\end{array}$ & $\begin{array}{c}\boldsymbol{\mu} \\
{\left[\mathbf{c m}^{-2}\right]}\end{array}$ & $\begin{array}{c}\boldsymbol{\Theta}(\mathbf{p F}=\mathbf{1 . 7}) \\
{\left[\mathbf{c m}^{\mathbf{3}} / \mathbf{c m}^{\mathbf{3}}\right]}\end{array}$ & $\begin{array}{c}\boldsymbol{\Theta}(\mathbf{p F}=\mathbf{2 . 0}) \\
{\left[\mathbf{c m}^{\mathbf{3}} / \mathbf{c m}^{\mathbf{3}}\right]}\end{array}$ \\
\hline coarse sand & 0.395 & 0.1000 & 0.085 & 0.047 \\
fine sand & 0.364 & 0.0288 & 0.234 & 0.198 \\
loamy sand & 0.439 & 0.0330 & 0.265 & 0.218 \\
fine loamy sand & 0.504 & 0.0207 & 0.367 & 0.325 \\
silty loam & 0.509 & 0.0185 & 0.383 & 0.344 \\
loam & 0.503 & 0.0180 & 0.382 & 0.343 \\
loess loam & 0.455 & 0.0169 & 0.351 & 0.318 \\
sandy clay loam & 0.432 & 0.0096 & 0.373 & 0.352 \\
silty clay loam & 0.475 & 0.0105 & 0.404 & 0.380 \\
clay loam & 0.445 & 0.0058 & 0.407 & 0.393 \\
light clay & 0.453 & 0.0085 & 0.398 & 0.378 \\
silty clay & 0.507 & 0.0065 & 0.459 & 0.442 \\
heavy clay & 0.54 & 0.0042 & 0.506 & 0.494 \\
peat (variable) & 0.863 & 0.0112 & 0.727 & 0.681 \\
\hline
\end{tabular}


Table 3. Values of the SMD threshold determining the division into wet and dry soil $R_{g}$, for the specified soils with the thickness of $0.30 \mathrm{~m}$

\begin{tabular}{c|c}
\hline Type of soil & $\mathbf{R}_{\mathbf{g}}[\mathbf{m m}]$ \\
\hline sand & 11.2 \\
loamy sand & 14.1 \\
fine loamy sand & 12.7 \\
silty loam & 11.9 \\
loam & 11.5 \\
loess loam & 10.0 \\
sandy clay loam & 6.2 \\
silty clay loam & 7.3 \\
clay loam & 4.1 \\
light clay & 5.8 \\
silty clay & 5.2 \\
heavy clay & 3.7 \\
peat (variable) & 14.0 \\
\hline
\end{tabular}

\section{Results}

Relative number of days with precipitation, calculated as ratio between average number of days with precipitation and growing season lengths, for Raba river catchment equals 0.458 .

Four soil maps for individual soil depth layers according to SoilGrids250m: 0, 5, 15, $30 \mathrm{~cm}$ were developed for the Raba river catchment. Differences observed in soil classification for the elaborated maps did not exceeded 1\%. Therefore, in order to determine the wet-dry threshold $R_{g}$, an average value from four soil layers.

On the basis of the developed soil map (Figure 5), the values of the wet-dry threshold $R_{g}$ were calculated. The wet-dry thresholds for the GLEMOK descriptor were determined for all sub-catchments (up to the water gauge, and the outflow to the Vistula river). For most of these sub-catchments, the calculated value of the threshold between wet and dry soil $R_{g}$ is set at $11.5 \mathrm{~mm}$. The following constitute an exception: catchment of the Stradomka river up to the Stradomka cross-section, where $R_{g}=11.7 \mathrm{~mm}$ and the Raba river catchment up to the Proszówki cross-section, where $R_{g}=11.6 \mathrm{~mm}$ (Table 4). For the whole area of Poland $R_{g}=9.1 \mathrm{~mm}$. Raster maps of soils/Rg for Poland can be downloaded from project web page (https://gitlab.com/OpenHydrology/soil-map).

Table 4. Values of the threshold between wet and dry soil for the GLEMOK descriptor for the Raba river catchment

\begin{tabular}{c|c|c|c|c}
\hline No. & River & Gauge station & $\mathbf{A}\left[\mathbf{k m}^{2}\right]$ & $\mathbf{R}_{\mathbf{g}}[\mathbf{m m}]$ \\
\hline 1 & & Rabka & 91.8 & 11.5 \\
2 & & Mszana Dolna & 157.2 & 11.5 \\
3 & \multirow{3}{*}{ RABA } & Kasinka Mała & 353.2 & 11.5 \\
4 & & Stróża & 643.7 & 11.5 \\
5 & & Proszówki & 1471.8 & 11.6 \\
6 & & outflow to Wisła & 1537.1 & 11.5 \\
\hline 7 & MSZANKA & Mszana Dolna & 151.5 & 11.5 \\
\hline 8 & LUBIEŃKA & Lubień & 47.8 & 11.5 \\
\hline 9 & KRZCZONÓWKA & Krzczonów & 87.3 & 11.5 \\
\hline 10 & STRADOMKA & Stradomka & 362.9 & 11.7 \\
\hline
\end{tabular}


It was found that for the catchment of the Raba river up to the Proszówki water gauge, the increase in the $R_{g}$ value from $11.5 \mathrm{~mm}$ to $11.6 \mathrm{~mm}$ does not affect the GLEMOK value, whereas for the Stradomka river catchment up to the Stradomka section, the GLEMOK value increases by 0.002 . This is considered a slight increase, and it has been assumed that in the whole Raba river catchment, the value determining the threshold between wet and dry soil can be set at $R_{g}=11.5 \mathrm{~mm}$. Table 5 presents the values of the calculated PCDs: PROPWET, FLATWET and GLEMOK, for individual sub-catchments of the Raba river.

Table 5. Values of the PROPWET, FLATWET and GLEMOK descriptors in the Raba river catchment, determined for the period of 1983-2012, and for the adopted fixed threshold between wet and dry soil (the subscript of the descriptor)

\begin{tabular}{c|c|c|c|c|c|c}
\hline No. & River & Gauge station & $\begin{array}{c}\mathbf{A} \\
{\left[\mathbf{k m}^{2}\right]}\end{array}$ & $\begin{array}{c}\text { PROPWET 6.0 } \\
{[-]}\end{array}$ & $\begin{array}{c}\text { FLATWET8.5 } \\
{[-]}\end{array}$ & $\begin{array}{c}\text { GLEMOK 11.5 } \\
{[-]}\end{array}$ \\
\hline 1 & & Rabka & 91.8 & 0.354 & 0.441 & 0.535 \\
2 & & Mszana Dolna & 157.2 & 0.352 & 0.427 & 0.514 \\
3 & \multirow{3}{*}{ RABA } & Kasinka Mała & 353.2 & 0.338 & 0.413 & 0.505 \\
4 & & Stróża & 643.7 & 0.326 & 0.406 & 0.486 \\
5 & & Proszówki & 1471.8 & 0.254 & 0.310 & 0.366 \\
6 & & outlet to Wisła & 1537.1 & 0.263 & 0.312 & 0.411 \\
\hline 7 & & Mszana Dolna & 151.5 & 0.329 & 0.408 & 0.495 \\
\hline 8 & LUSZANKA & Lubień & 47.8 & 0.326 & 0.404 & 0.491 \\
\hline 9 & KRZCZONÓWWA & Krzczonów & 87.3 & 0.319 & 0.394 & 0.477 \\
\hline 10 & STRADOMKA & Stradomka & 362.9 & 0.178 & 0.225 & 0.308 \\
\hline
\end{tabular}

Based on the obtained results, a comparison was made between PROPWET, FLATWET and GLEMOK descriptors for all sub-catchments, determining absolute and relative changes. The relative increment in the GLEMOK value in relation to the PROPWET and FLATWET was calculated based on the following formula:

$$
F L A T_{G L E}=\frac{G L E-F L A T}{F L A T} 100 \text { and } P R O P_{G L E}=\frac{G L E-P R O P}{P R O P}
$$

where:

- FLAT $_{G L E}\left(P R O P_{G L E}\right)$ - increment of the GLEMOK 11.5 descriptor compared to FLATWET $_{8,5}$ or PROPWET $_{6.0}$.

- $G L E$ - value of the GLEMOK 11.5 descriptor (-)].

- FLAT $(P R O P)$ - value of the FLATWET $_{8.5}$ descriptor or the PROPWET $_{6.0}$ descriptor (-).

The variability of the analysed descriptors is related to the topography of the area (Figure 6). The highest values of all descriptors can be observed in the upper (southern) parts of the Raba river catchment. Descriptors changes are visible, clearly dividing the catchment into two parts: mountains and uplands (Figure 6). The lowest values of all descriptors were obtained for the Stradomka river catchment, up to the Stradomka cross-section. This is probably due to the fact that there are lower precipitation heights in this catchment (Table 1) than in the remaining area, hence the relative increase in the value of the GLEMOK, as compared to PROPWET value, exceeds $70 \%$. 
Table 6. The absolute and the relative increment of the GLEMOK descriptor value compared to the value of the PROPWET and FLATWET descriptors

\begin{tabular}{c|c|c|c|c|c|c}
\hline \multirow{2}{*}{ No. } & \multirow{2}{*}{ River } & \multirow{2}{*}{ Gauge station } & \multicolumn{2}{|c}{ FLAT } & \multicolumn{3}{|c}{ PROP } & \multicolumn{2}{c}{ PLE } \\
\cline { 3 - 6 } & & & {$[-]$} & {$[\%]$} & {$[-]$} & {$[\%]$} \\
\hline 1 & & Rabka & 0.094 & 21.3 & 0.181 & 51.0 \\
2 & & Mszana Dolna & 0.087 & 20.3 & 0.162 & 46.0 \\
3 & \multirow{3}{*}{ RABA } & Kasinka Mała & 0.092 & 22.2 & 0.167 & 49.3 \\
4 & & Stróża & 0.080 & 19.7 & 0.160 & 48.9 \\
5 & & Proszówki & 0.056 & 18.2 & 0.113 & 44.5 \\
6 & & outlet to Wisła & 0.099 & 31.6 & 0.148 & 56.3 \\
\hline 7 & MSZANKA & Mszana Dolna & 0.087 & 21.3 & 0.167 & 50.7 \\
\hline 8 & LUBIEŃKA & Lubień & 0.087 & 21.5 & 0.164 & 50.4 \\
\hline 9 & KRZCZONÓWKA & Krzczonów & 0.082 & 20.8 & 0.157 & 49.3 \\
\hline 10 & STRADOMKA & Stradomka & 0.082 & 36.5 & 0.129 & $\mathbf{7 2 . 4}$ \\
\hline
\end{tabular}

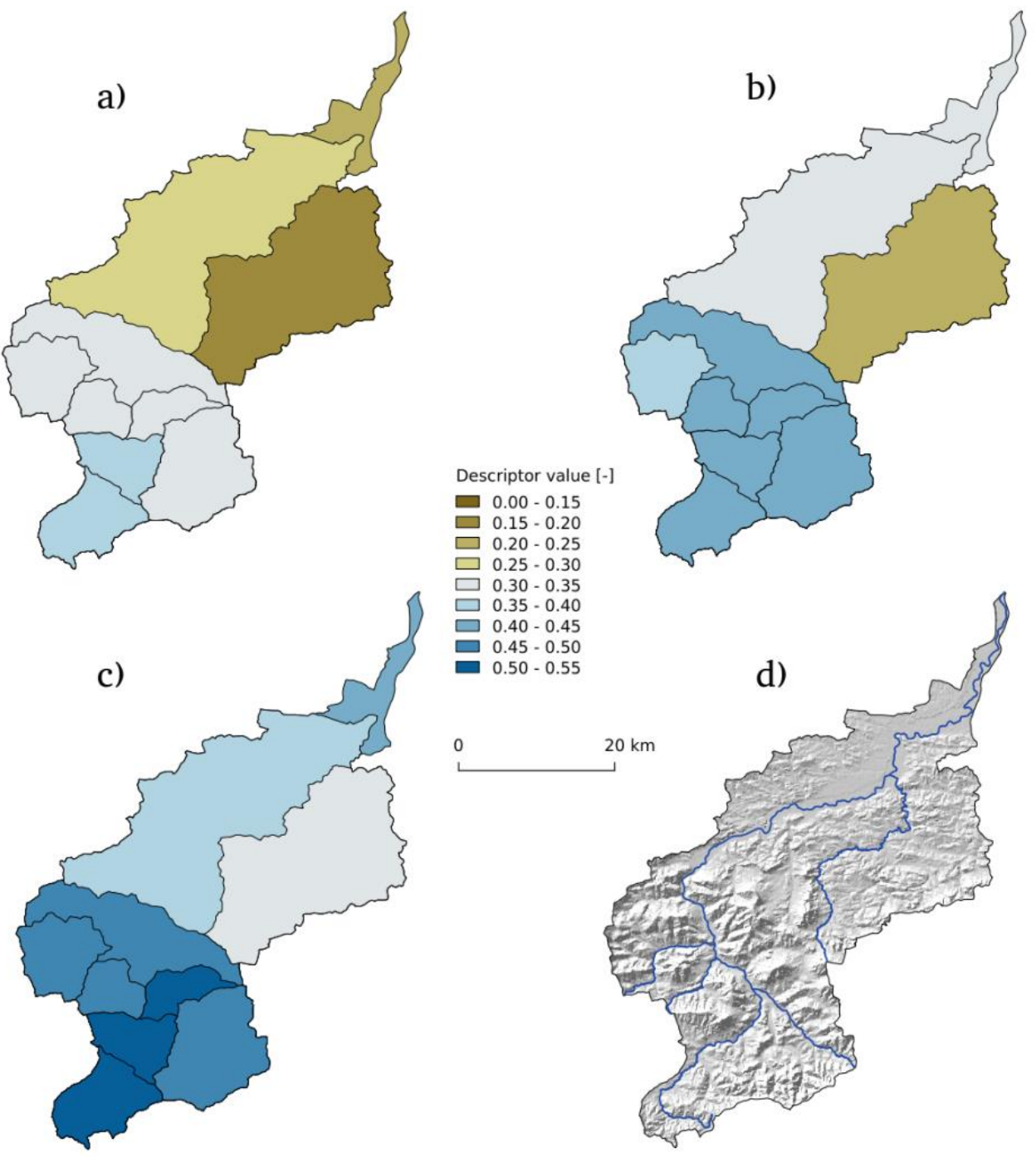

Figure 6. Spatial variability for the sub-catchments of the Raba river catchment, according to: a) PROWET, b) FLATWET, c) GLEMOK; d) topography of the Raba river catchment 


\section{Discussion}

In the PROPWET and FLATWET descriptors calculation method, the wet-dry threshold $R_{g}$ is determined using statistical analysis, as constant value for the whole area in analysed period. According to authors of PROPWET for Ireland "the choice of wetdry threshold is rather arbitrary" (Reed, 2007).

The assumption that the threshold is constant in time and space, means that the ratio between precipitation and evaporation is maintained. When this ratio changes, the value of the wet-dry threshold $R_{g}$ must be updated (Bayliss and Morris, 1999). These changes may be caused, among others by the climate change. The maximum daily precipitation changes have been documented in the studied area (Kundzewicz et al., 2005; Młyński et al., 2018) so direct implementation of PROPWET and FLATWET in Poland would be impractical.

The PROPWET values in the United Kingdom ranges from 0.51 to 0.75 . Despite the high variability of the PROPWET value, one wet-dry threshold value $R_{g}=6 \mathrm{~mm}$ was adopted (Reed, 2007). The wet-dry PROPWET threshold for the Ireland $8.5 \mathrm{~mm}$ was obtained. As a result, a new FLATWET descriptor was created with values from 0.55 to 0.74, referring only to the area of Ireland (Mills et al., 2014). Thus the various wet-dry threshold values for the PROPWET descriptors in the United Kingdom and FLATWET in Ireland indicate their regional nature. High descriptors values for relatively low $R_{g}$ can be caused by higher precipitation for British Isles compared to Poland. Implementation of PROPWET and FLATWET descriptors in other area would required wet-dry threshold $R_{g}$ determination for long-term data series from several climatologic stations.

To check regional nature and spatial variability of descriptors, the Raba river catchment $\left(\mathrm{A}=1537 \mathrm{~km}^{2}\right)$ with its sub-catchments was selected as research area.

Since the descriptors refer to the soil moisture condition, the parameter considering the soil type should be taken into account in the calculation process. The soil types are variable in space and soil data are available worldwide. The adopted method for determining the soil type, based on the physical soil parameters from the SoilGrids $250 \mathrm{~m}$ database (Hengl et al., 2017), enables the universal use of the GLEMOK descriptor. Value of this descriptor is based on the unambiguous determination of wet-dry threshold $R_{g}$, from type of soil and $\mathrm{pF}$ curves.

The wet-dry threshold $R_{g}$ in Poland ranges from 6.2 to $14.1 \mathrm{~mm}$ with the average value $9.1 \mathrm{~mm}$. For Raba river catchment the variability of $R_{g}$ is small - maximum difference equals $0.2 \mathrm{~mm}$ (Table 4). It has been shown that even in such a small area compared to Ireland or United Kingdom, there is spatial variability in the values of the PROPWET, FLATWET and GLEMOK descriptors (Figure 6). The values are: for the PROPWET - from 0.178 to 0.354 , for the FLATWET - from 0.225 to 0.441 , and for the GLEMOK - from 0.308 to 0.535 (Table 5). Descriptors values should correspond to number of days with precipitation. For longer precipitation period descriptors values should be higher. It corresponds to wet soil conditions, when river supply comes mainly from surface and sub-surface runoff. In the remaining period, dry soil represents river supply only from groundwater.

The average number of days with precipitation in the analysed period is 98 per growing season in the Raba river catchment. The precipitation indicator determining the number of precipitation days for the growing season (214 days) equals 0.458 . Therefore, it would be expected that the values of these descriptors will not be lower than the precipitation indicator. For the analysed area of Raba river catchment, this assumption 
for PROPWET and FLATWET descriptors is not fulfilled - in both cases the values are lower than the precipitation indicator. However, precipitation indicator is in the range of GLEMOK descriptor values. Taking into account the physical soil properties (like in GLEMOK) results are more reliable.

Low values of PROPWET and FLATWET descriptors in the Raba river catchment imply that groundwater is the main source of water supply, which is not true.

The spatial variability of all three descriptors reflects the character of spatial variability of precipitation and evapotranspiration. The difference between GLEMOK and the other two descriptors is based on a different method of determining the wet-dry threshold $R_{g}$. Only GLEMOK descriptor includes local physical soil properties.

According to the authors, determining the value of the threshold $R_{g}$ on the basis of physical properties of soils and the $\mathrm{pF}$ curve is more justified than statistical methods used to determine the PROPWET and FLATWET descriptors.

\section{Conclusion}

The wet-dry threshold $R_{g}$ is a key parameter in determination of all three descriptors - PROPWET, FLATWET, GLEMOK. Calculation of wet-dry threshold value in PROPWET $\left(R_{g}=6.0\right)$ and FLATWET $\left(R_{g}=8.5\right)$ is based on meteorological records, which are combined into averaged value over whole research area. In GLEMOK descriptor this value ( $R_{g}=11.5$ for the Raba river catchment, $R_{g}=9.1$ for Poland) is calculated from spatial distribution of meteorological records but additional information on soil types is provided. Difference in $R_{g}$ values between British Isles and Poland is result of both climate and soil type.

Relative difference of the GLEMOK value in relation to the PROPWET is about $50 \%$, whereas compared to the FLATWET, it is about 20\% (Figure 6).

The GLEMOK descriptor better adopts runoff values comparing to those expected from the other two descriptors. Direct implementation of PROPWET or FLATWET for the area of Poland would cause unreliable water regime which is based on groundwater supply.

Direct implementation of PROPWET and FLATWET to locations outside British Isles requires long-term series of meteorological data from several stations. Implementation of GLEMOK is possible with data from just single meteorological station. It is a great advantage of proposed GLEMOK method.

The new method using the GLEMOK descriptor is more universal compared to PROPWET and FLATWET. Use of the global SolidGrids $250 \mathrm{~m}$ soil database enables implementation of this method in any area in Europe.

\section{REFERENCES}

[1] Allen, R. G., Pereira, L. S., Raes, D., Smith, M. (1998): Crop evapotranspiration (guidelines for computing crop water requirements). - FAO Irrigation and Drainage Paper 56.

[2] Apel, H., Thieken, A. H., Merz, B., Blöschl, G. (2006): A Probabilistic Modelling System For Assessing Flood Risks. - Natural Hazards 38: 295-308.

[3] Bayliss, A. C. (1999): Catchment descriptors. - Volume 5 of the Flood Estimation Handbook. Center for Ecology \& Hydrology. 
[4] Bayliss, A. C., Morris, S. E. (1999): Climate and soils. - Chapter 5 of FEH Vol. 5 Catchment descriptors. IH, Wallingford: 27-38.

[5] Driessen, P. M. (1986): The water balance of soil. - In: van Keulen, H., Wolf, J. (eds.) Modeling of agricultural production: weather, soils and crops. Simulation Monographs. Pudoc, Wageningen: 76-116.

[6] Eagleson, P. (1970): Dynamic Hydrology - McGraw-Hill.

[7] Faulkner, D. (1999): Rainfall frequency estimation. - Volume 2 of the Flood Estimation Handbook. Center for Ecology \& Hydrology.

[8] Harper, M., Weinstein, B., Simon, C., Morgan, W., Knight, V., Swanson-Hysell, N., Evans, M., Anglo, S., Greco, M., Zuidhof, G. (2015): Python-ternary: ternary Plots in Python. - Zenodo. 10.5281/zenodo.34938.

[9] Hengl, T., Mendes de Jesus, J., Heuvelink, G. B. M., Ruiperez Gonzalez, M., Kilibarda, M., Blagotić, A., Shangguan, W., Wright, M. N., Geng, X., Bauer-Marschallinger, B., Guevara, M. A., Vargas, R., MacMillan, R. A., Batjes, N. H., Leenaars, J. G. B., Ribeiro, E., Wheeler, I., Mantel, S., Kempen, B. (2017): SoilGrids250m: Global gridded soil information based on machine learning. - PLoS ONE 12(2): e0169748. https://doi.org/10.1371/journal.pone.0169748.

[10] Houghton-Carr, H. (1999): Restatement and application of the Flood Studies Report rainfall-runoff method. - Volume 4 of the Flood Estimation Handbook. Center for Ecology \& Hydrology.

[11] Hubbard, K. G., You, J., Hunt, E. D. (2007): Development of the Soil Moisture Index to Quantify Agricultural Drought and Its "User Friendliness" in Severity-Area-Duration Assessment. - Journal of Hydrometeorology 9: 660-676.

[12] IMGW (1987): Atlas hydrologiczny Polski. - tom I (The hydrological Atlas of Poland vol. I).

[13] Kejna, M., Araźny, A., Maszewski, R., Przybylak, R., Uscka-Kowalkowska, J., Vizi, Z. (2009): Daily minimum and maximum air temperature in Poland in the years 1951-2005. - Bulletin of Geography. Physical Geography Series 2(1): 35-56.

[14] Kottek, M., Grieser, J., Beck, C., Rudolf, B., Rubel, F. (2006): World map of the Köppen-Geiger climate classification updated. - Meteorologische Zeitschrift 15(3): 259263.

[15] Kundzewicz, Z. W., Ulbrich, U., Brücher, T., Graczyk, D., Krüger, A., Leckebusch, G. C., Menzel, L., Pińskwar, I., Radziejewski, M., Szwed, M. (2005): Summer floods in Central Europe - climate change track? - Nat. Hazards 36(1/2): 165-189. DOI: 10.1007/s11069-004-4547-6.

[16] Mills, P., Nicholson, O., Reed, D. (2014): Flood Studies Update, Technical Research Report. Vol. IV. Physical Catchment Descriptors. - Based on research reports by Compass Informatics. DWRconsult and OPW.

[17] Młyński, D., Cebulska, M., Wałęga, A. (2018): Trends, Variability, and Seasonality of Maximum Annual Daily Precipitation in the Upper Vistula Basin, Poland. - Atmosphere 9: 313. doi:10.3390/atmos9080313.

[18] Narasimhan, B., Srinivasan, R. (2005): Development and evaluation of Soil Moisture Deficit Index (SMDI) and Evapotranspiration Deficit Index (ETDI) for agricultural drought monitoring. - Agricultural and Forest Meteorology 133(1): 69-88.

[19] Noone, S., Murphy, C., Coll, J., Matthews, T., Mullan, D., Wilby, R. L., Walsh, S. (2016): Homogenization and analysis of an expanded long-term monthly rainfall network for the Island of Ireland (1850-2010). - International Journal of Climatology 36(8): 28372853.

[20] O'Connor, K., Goswami, M., Faulkner, D. (2014): Flood Studies Update. - Technical Research Report, Volume III, Hydrograph Analysis, pp 186.

[21] Olszewski, K., Żmudzka, E. (2000): Variability of the vegetative period in Poland. Miscellanea Geographica 9.1: 59-70. 
[22] Ozga-Zielińska, M., Gądek, W., Książyński, K., Nachlik, E., Szczepanek, R. (2002): Mathematical Model Of Rainfall-Runoff Transformation - WISTOO. - In: Singh, V. P., Frevert, D. K. (eds.) Mathematical Models Of Large Watershed Hydrology. Water Resources Publications, LLC, Littleton, Colorado: 811-860.

[23] Reed, D. (1999): Overview. - Volume 1 of the Flood Estimation Handbook. Center for Ecology \& Hydrology.

[24] Reed, D. (2007): Flood Studies Update Work-Package 5.4. Report to OPW. PROPWET for Ireland: A dimensionless index of typical catchment wetness. - Wallingford.

[25] Robson, A., Reed, D. (1999): Statistical procedures for flood frequency estimation. Volume 3 of the Flood Estimation Handbook. Center for Ecology \& Hydrology.

[26] Schulte, R. P. O., Diamond, J., Finkele, K., Holden, N. M., Brereton, A. J. (2005): Predicting the Soil Moisture Conditions of Irish Grasslands. - Irish Journal of Agricultural Research 44: 95-110.

[27] Sherman, G. (2014): The PyQGIS Programmer's Guide Extending QGIS 2.x with Python. - Locate Press LLC.

[28] Vrijling, J. K., Van Hengel, W., Houben, R. J. (1998): Acceptable Risk As A Basis For Design. - Reliability Engineering And System Saferty 59: 141-150.

[29] Yue, S., Wang, C. (2002): The influence of serial correlation on the Mann-Whitney test for detecting a shift in median. - Advances in Water Resources 25(3): 325-333.

[30] Zeleňáková, M., Gaňová, L., Purcz, P., Horský, M. (2017): Mitigation of the Adverse Consequences of Floods for Human Life. - Infrastructure, and the Environment, Natural Hazards Review 18(4).

[31] Zevenbergen, C., Cashman, A., Evelpidou, N., Pasche, E., Garvin, S., Ashley, R. (2011): Urban Flood Management. - CRC Press London. 